\title{
Succinic acid-producing biofilms of Actinobacillus succinogenes: reproducibility, stability and productivity
}

\author{
K. Maharaj, M.F.A. Bradfield, W. Nicol* \\ Department of Chemical Engineering, University of Pretoria, Lynnwood Road, Hatfield, \\ 0002, Pretoria, South Africa
}

Postal address: Department of Chemical Engineering, University of Pretoria, Private Bag X20, Hatfield, 0028, South Africa

E-mail addresses:

Prof W. Nicol; corresponding author: willie.nicol@up.ac.za

Ms K. Maharaj: karishma.maharaj@gmail.com

Mr M.F.A Bradfield: michael.bradfield@ @uks.co.za

*Corresponding author. Tel.: +27 12420 3796; fax: +12 420 5048. E-mail address:

willie.nicol@up.ac.za 


\begin{abstract}
Continuous anaerobic fermentations were performed in a biofilm reactor packed with Poraver ${ }^{\circledR}$ beads. Dilution rates (D) varied between $0.054 \mathrm{~h}^{-1}$ and $0.72 \mathrm{~h}^{-1}$ and $\mathrm{D}$-glucose and $\mathrm{CO}_{2}$ gas were used as carbon substrates. Steady-state conditions were shown to be repeatable and independent of the operational history. Production stability was achieved over periods exceeding $80 \mathrm{~h}$ at values of $\mathrm{D}$ below $0.32 \mathrm{~h}^{-1}$. In these situations, steady-state variation (expressed as fluctuations in $\mathrm{NaOH}$ neutralisation flow rates) exhibited a standard deviation of less than $5 \%$ while no indication of biofilm deactivation was detected. The total biomass amount was found to be independent of the dilution rate with an average dry concentration of $23.8 \pm 2.9 \mathrm{~g} \mathrm{~L}^{-1}$ obtained for all runs. This suggests that the attachment area controls the extent of biofilm accumulation. Specific succinic acid (SA) productivities, based on the total biomass amount, exhibited a substantial decrease with decreasing D. An SA volumetric productivity of $10.8 \mathrm{~g} \mathrm{~L}^{-1} \mathrm{~h}^{-1}$ was obtained at $\mathrm{D}=0.7 \mathrm{~h}^{-1}$ - the highest value reported to date in A. succinogenes fermentations. SA yields on glucose increased with decreasing D, with a yield of $0.90 \pm 0.01 \mathrm{~g} \mathrm{~g}^{-1}$ obtained at a $\mathrm{D}$ of $0.054 \mathrm{~h}^{-1}$. Production of formic acid approached zero with decreasing $\mathrm{D}$, while the succinic- to acetic acid ratio increased with decreasing $\mathrm{D}$, resulting in an increasing SA yield on glucose.
\end{abstract}

\title{
Keywords
}

Actinobacillus succinogenes; biofilm reactor; continuous fermentation; productivity; stability; succinic acid 


\section{Introduction}

Currently, the main industrial application for biofilm reactors is for the treatment of wastewater and off-gas (Qureshi et al. 2005). A number of review papers recently highlighted the potential of single culture biofilm reactors for the production of speciality and bulk chemicals (Cheng et al. 2010; Gross et al. 2007; Qureshi et al. 2005; Rosche et al. 2009). The self-immobilisation nature of some microbial strains has the advantage that cell-retainment within a bioreactor can be achieved without any active cell-separation scheme. The result is that high volumetric productivities can be achieved at a relatively low bioreactor cost (Rosche et al. 2009). This is of specific interest for bulk-scale continuous processes where the bioreactor cost is closely linked to the economic viability of the process. Given the global interest in bio-based chemicals and fuels (Fernando et al. 2006) where fermentation steps are readily employed in the conversion of sugars and lignocellulosic biomass, high cell density fermentation is seen in a new light where the continuous biofilm reactor may play an important role. Apart from the productivity advantage, biofilms are known for long term activity and enhanced tolerance to toxic reactants (Gross et al. 2007) - properties favourable for continuous processing where biocatalyst stability is a major concern.

Succinic acid (SA) requires no introduction as a bio-based platform chemical. It has featured in the US Department of Energy's original 'top-ten bio-based chemicals' list (Werpy and Petersen 2004) and also features on the updated list (Bozell and Petersen 2010). It has numerous applications (Cukalovic and Stevens 2008) but the largest potential lies in the replacement of intermediate chemicals such as tetrahydrofuran, 1,4-butanediol and maleic anhydride (Zeikus et al. 1999) and various bio-based polymers (Bechthold et al. 2008). The global bio-based SA market is expected to reach 840 million USD by 2018 (TransparencyMarket-Research 2013). Most of the studies performed on SA fermentation employ wild 
bacterial strains and modified strains of Escherichia coli (Beauprez et al. 2010). Due to the $\mathrm{CO}_{2}$ fixation step in the production of $\mathrm{SA}$ it is theoretically possible to obtain 1.12 grams of SA per gram of glucose (van Heerden and Nicol 2013a). Modified E. coli batch fermentations have exceeded the $1 \mathrm{~g} \mathrm{~g}^{-1}$ threshold (Balzer et al. 2013; Jantama et al. 2008) although no report exists where this threshold has been exceeded with a continuous culture. $A$. succinogenes is by far the most reported SA producing bacterial strain, although only four studies report on the continuous culture (Bradfield and Nicol 2014; Van Heerden and Nicol 2013b; Kim et al. 2009; Urbance et al. 2004).

Biofilm formation appears to be unavoidable for long-term continuous cultures of $A$. succinogenes (Bradfield and Nicol 2014; Van Heerden and Nicol 2013b) and is a possible reason why Kim et al. (2009) experienced severe membrane fouling within $50 \mathrm{~h}$ of continuous operation in a cell-recycle fermenter. Attempts to operate in a chemostat mode by removing internal packing were unsuccessful due to biofilm attachment on the glass and metal surfaces of the reactor (Van Heerden and Nicol 2013b). Considering that immobilisation is guaranteed after a few days of continuous operation, the focus should rather be on employing an attachment surface that facilitates process stability and performance. Various types of support packing have proven successful for single culture biofilm fermentations. Superior results were obtained with Poraver® porous glass beads (Dagher et al. 2010; Dishisha et al. 2012), Vukopor® and polyurethane foam (Casali et al. 2012).

In continuous fermentations, dilution rate is often used as the independent variable to define the throughput on the basis of the fermenter volume. However, both Van Heerden and Nicol (2013b) and Bradfield and Nicol (2014) report a major variation in bioreactor performance given a controlled dilution rate. Although steady-states were achieved in both studies, repeatability of the steady-states per dilution rate could not be achieved. This can be 
attributed to the instability of the biofilm in the bioreactor and the inability to sustain a uniform biofilm and/or a consistent amount of metabolically active cells. Furthermore, the mentioned studies did not attempt to quantify the total biomass content in the reactor. This measurement is more complex than the corresponding suspended cell measurement in a chemostat where the outflow cell concentration represents the cell concentration in the reactor. Complete termination of the fermentation is required in order to remove all attached biomass for an overall biomass measurement. Therefore, to date no studies on continuous $A$. succinogenes fermentation have successfully addressed the questions of whether reactor performance in a packed biofilm reactor is repeatable and related to the dilution rate, and what the influence of the total biomass concentration is on SA production.

In the present work, the production repeatability, stability and total biomass content in a biofilm reactor, packed with Poraver®, were studied under continuous operation at a range of controlled dilution rates. Steady-state stability was analysed over extended periods (> $80 \mathrm{~h})$. The performance of the reactor, as a function of dilution rate, was analysed in terms of yield, titre, by-product distribution and SA productivity. 


\section{Materials and Methods}

\section{Microorganism}

Actinobacillus succinogenes 130Z (DSM 22257 or ATCC 55618) was obtained from the German Collection of Microorganisms and Cell Cultures (DSMZ). Vials containing treated beads in a cryopreservation solution were used to store culture samples at $-75^{\circ} \mathrm{C}$. Inoculum was incubated at $37{ }^{\circ} \mathrm{C}$ and $100 \mathrm{rpm}$ for $16-24 \mathrm{~h}$ in $30-\mathrm{mL}$ sealed vials containing $15 \mathrm{~mL}$ sterilised tryptone soy broth (TSB).

\section{Growth Medium}

All chemicals were obtained from Merck KgaA (Darmstadt, Germany), unless otherwise indicated. The fermentation medium consisted of three parts: a growth medium, a phosphate buffer and glucose. The growth medium, based on Urbance et al. (2003), had the following composition: $6.0 \mathrm{~g} \mathrm{~L}^{-1}$ yeast extract, $10.0 \mathrm{~g} \mathrm{~L}^{-1}$ clarified corn steep liquor (Sigma-Aldrich, St. Louis, USA), $1.0 \mathrm{~g} \mathrm{~L}^{-1} \mathrm{NaCl}, 0.2 \mathrm{~g} \mathrm{~L}^{-1} \mathrm{MgCl}_{2} \cdot 6 \mathrm{H}_{2} \mathrm{O}, 0.2 \mathrm{~g} \mathrm{~L}^{-1} \mathrm{CaCl}_{2} \cdot 2 \mathrm{H}_{2} \mathrm{O}, 1.36 \mathrm{~g} \mathrm{~L}^{-1}$ sodium acetate, and $1.0 \mathrm{~mL}$ Antifoam A (Sigma-Aldrich. St. Louis, USA). $\mathrm{Na}_{2} \mathrm{~S} \cdot 9 \mathrm{H}_{2} \mathrm{O}$ was excluded as it was assumed that the $\mathrm{CO}_{2}$ flowrate $(7 \%$ vvm) was sufficient to maintain anaerobic conditions. Corn steep liquor was clarified by boiling a $200 \mathrm{~g} \mathrm{~L}^{-1}$ solution at $105{ }^{\circ} \mathrm{C}$ for 15 min and allowing the solids to precipitate during cooling. Once cooled, the supernatant was removed and used for the growth medium. The phosphate buffer consisted of $3.0 \mathrm{~g} \mathrm{~L}^{-1}$ $\mathrm{K}_{2} \mathrm{HPO}_{4}, 0.31 \mathrm{~g} \mathrm{~L}^{-1} \mathrm{Na}_{2} \mathrm{HPO}_{4}$ and $1.6 \mathrm{~g} \mathrm{~L}^{-1} \mathrm{NaH}_{2} \mathrm{PO}_{4}$. Glucose was added to the medium at approximately $35 \mathrm{~g} \mathrm{~L}^{-1}$ for high dilution rates $\left(\geq 0.3 \mathrm{~h}^{-1}\right)$ and $60 \mathrm{~g} \mathrm{~L}^{-1}$ for low dilution rates $\left(<0.3 \mathrm{~h}^{-1}\right)$ to avoid substrate limitation. $\mathrm{CO}_{2}(\mathrm{~g})$ (Afrox, Johannesburg, South Africa) was fed into the recycle line at $7 \%$ vvm to serve as the inorganic carbon source. 


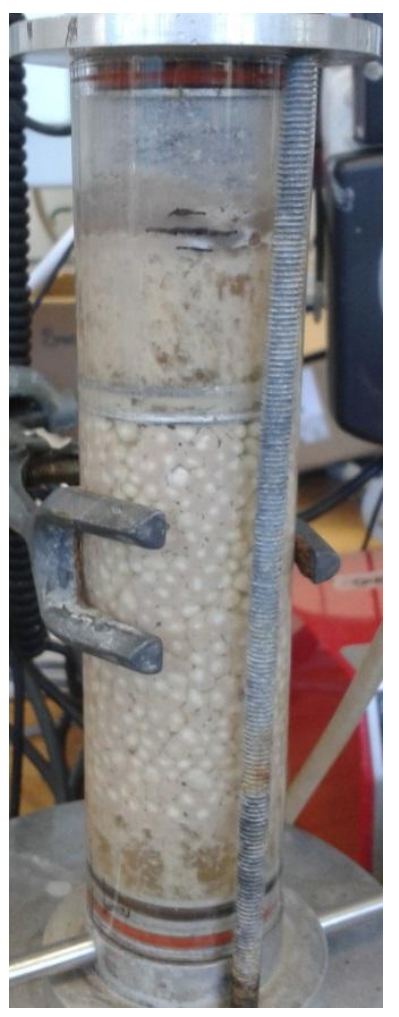

Fig. 1 The bioreactor during a fermentation. The Poraver® packing can be seen as the circular white beads. Biofilm can be seen on the glass and the packing. A perforated plate (above the level of the packing) was used to hold the packing in place. 


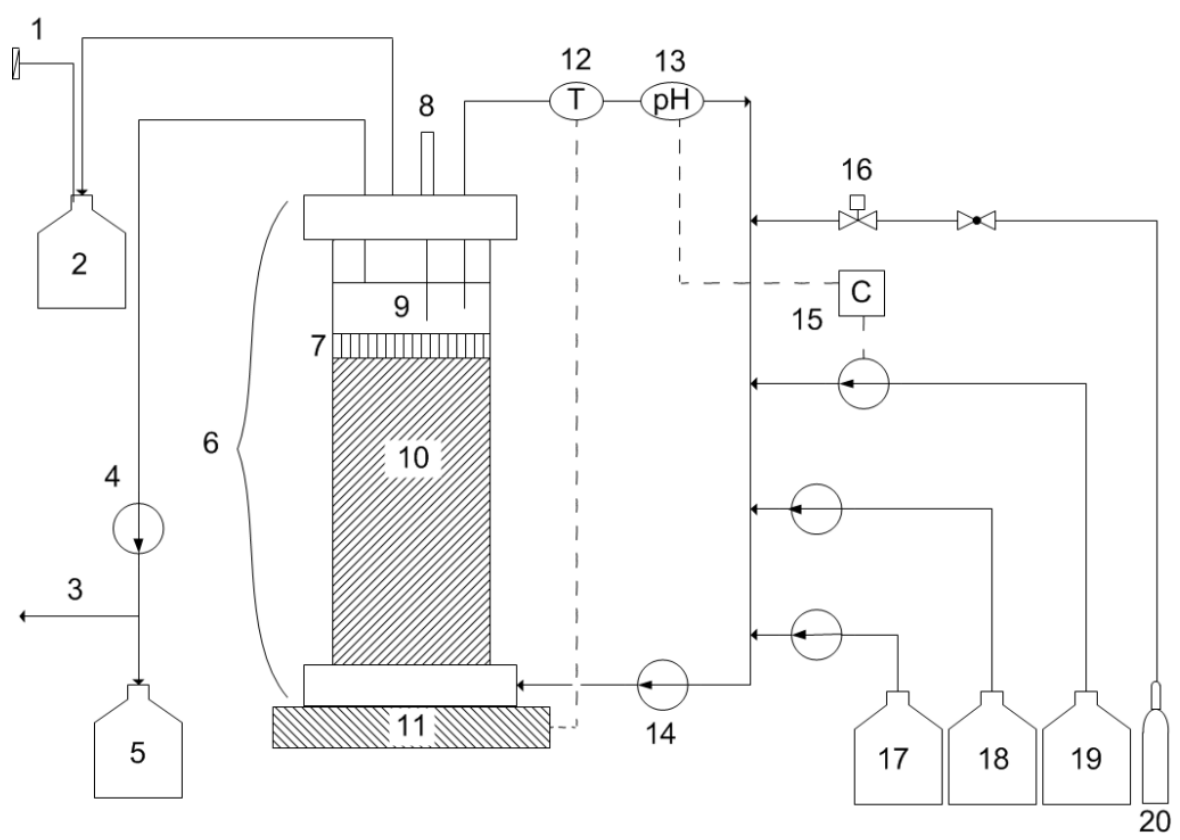

\begin{tabular}{ll}
\hline No. & Description \\
\hline 1 & Gas filter \\
2 & Foam-trap \\
3 & Sample line \\
4 & Peristaltic pump \\
5 & Product reservoir \\
6 & Reactor body \\
7 & Perforated plate \\
8 & Inoculation septum \\
9 & Liquid head space \\
10 & Poraver@ packing \\
11 & Hot plate \\
12 & Thermocouple \& temp. \\
& controller \\
13 & pH probe \\
14 & Recycle pump \\
15 & pH controller \\
16 & Gas flow controller \\
17 & Medium reservoir \\
18 & Antifoam reservoir \\
19 & NaOH reservoir \\
20 & $\mathrm{CO}_{2}$ cylinder \\
\hline
\end{tabular}

Fig. 2 Schematic of the reactor setup used in the study (not to scale). 


\section{Fermentation}

The bioreactor, pictured in Fig. 1 and shown schematically in Fig. 2, consisted of a glass cylindrical body (44 mm outer diameter, $3.2 \mathrm{~mm}$ wall thickness) contained between an aluminium base and head. An external recycle line provided agitation. All compartments (reactor body, reservoirs, vents, etc.) of the system were connected using silicone tubing. The working volume of the reactor (including the recycle) was $165 \mathrm{~mL}$. A perforated stainlesssteel plate ( $3 \mathrm{~mm}$ triangular pitch) was inserted above the packing to prevent movement of the support particles through the recycle while allowing flow of liquid and gas. $\mathrm{pH}$ was controlled at 6.80 by dosing $10 \mathrm{M} \mathrm{NaOH}$ and temperature was controlled at $37^{\circ} \mathrm{C}$. Additional details on the reactor system (incl. $\mathrm{pH}$ and temperature control, and data acquisition) and the feed preparation method can be found in Bradfield and Nicol (2014).

Poraver® expanded glass particles (Dennert Poraver GmbH, Germany) were used as an attachment surface for $A$. succinogenes. The particle diameters ranged between $3 \mathrm{~mm}$ and $4 \mathrm{~mm}$ and had a bulk density of $190 \pm 20 \mathrm{~kg} \mathrm{~m}^{-3}$. The support particles occupied a volume of $\pm 65 \mathrm{~mL}$ (approx. $39 \%$ of the working volume). A constant mass (15.7 g) of dry support particles was used to ensure an approximately constant volume and surface area available for attachment. The recycle flow rate was kept constant at approximately $497 \mathrm{~mL} \mathrm{~min}^{-1}$ i fermentations to maintain similar shear conditions.

The entire working volume of the reactor system (tubing, reservoirs, reactor, initial feed, etc.), excluding $\mathrm{NaOH}$, was autoclaved at $121^{\circ} \mathrm{C}$. For $5 \mathrm{~L}$ of initial feed connected to the system, the autoclaving time was $40 \mathrm{~min}$, whereas for $10 \mathrm{~L}$ of initial feed, the autoclaving time was increased to 60 min. Feed was replenished online using a double-valve transfer coupling that was heat sterilised in oil at $140{ }^{\circ} \mathrm{C}$ for at least 20 min prior to the transferral of fresh feed. This allowed for extended fermentation times. Fresh feed was prepared and 
sterilised in the same way as the initial feed. Gas inlets and vents contained $0.2 \mu \mathrm{m}$ PTFE membrane filters (Midisart 2000, Sartorius, Göttingen, Germany) to ensure sterile gas flow across the system boundary. Poraver ${ }^{\circledR}$ particles were not pre-treated in any special way, only weighed for an initial mass measurement.

\section{Analytical methods}

High-performance liquid chromatography (HPLC) was used to determine the concentrations of glucose, ethanol and organic acids. Analyses were performed using an Agilent 1260 Infinity HPLC (Agilent Technologies, USA), equipped with an RI detector and a $300 \mathrm{~mm} \mathrm{x}$ 7.8 mm Aminex HPX-87 H ion-exchange column (Bio-Rad Laboratories, USA). The mobile phase $\left(0.3 \mathrm{~mL} \mathrm{~L}^{-1} \mathrm{H}_{2} \mathrm{SO}_{4}\right)$ flowrate was $0.6 \mathrm{~mL} \mathrm{~min}^{-1}$ and column temperature was $60{ }^{\circ} \mathrm{C}$.

Dry cell weight (DCW) was determined from 9-mL samples or 12-h to 24-h samples (volume of sample dependent on dilution rate) centrifuged at $12100 \mathrm{x} \mathrm{g}$ for $1.5 \mathrm{~min}$ and $3095 \mathrm{x} \mathrm{g}$ for $10 \mathrm{~min}$, respectively. Cell pellets were washed twice with distilled water and centrifuged between washes then dried at $85^{\circ} \mathrm{C}$ for at least $24 \mathrm{~h}$. The larger samples were collected under steady-state conditions only, during which the sampling bottle was immersed in ice in order to prevent further cell growth and inhibit metabolic activity.

Total biomass quantification necessitated termination of the fermentation. Recycle rates were increased substantially to scrub loose biofilm segments while liquid was transferred to the collection bottle. The Poraver® was removed and washed with distilled water in a separate container with all wash-liquid (of various washing batches) collected in a single collection bottle. Fermenter internals were washed in a similar manner until clean, with all the washliquid gathered in the collection bottle. The collection bottle was filled to $2 \mathrm{~L}$ with distilled water and homogenised by fast stirring. A $200-\mathrm{mL}$ sample of the homogenised liquid was 
used for DCW analysis. Washed Poraver ${ }^{\circledR}$ pellets (dry mass determined before fermentation) were dried in an oven at $85{ }^{\circ} \mathrm{C}$ for $24 \mathrm{~h}$ to determine the mass of biomass trapped within the pellets. Combined biomass weights from the collection bottle and the Poraver® pellets were divided by the reactor working volume to obtain the reported total DCW measurement.

\section{Mass balance closures}

Volume and component mass balances were used to assess the accuracy of the experimental data. Volume balances assumed a single density for all liquid streams. The calculation compared the actual volumetric throughput to the expected throughput, based on set feed flow rates and averaged $\mathrm{NaOH}$ dosing flow rates. All reported data have volume balances with an error less than $5 \%$ with an absolute average deviation of $2.1 \%$. Component mass balances were based on glucose and metabolite concentrations in the inlet and outlet streams. Suspended DCW measurements in the effluent were not considered due to poor repeatability. Mass balance results were expressed as theoretical glucose fed divided by measured glucose fed. Theoretical glucose was calculated by using measured metabolite and unconverted glucose concentrations. The mass balances closed to $99.3 \%$ on average with an average absolute deviation of $3.2 \%$ and a maximum absolute deviation of $8 \%$. Since suspended DCW measurements were neglected in the mass balance, it suggests that the steady-state carbon flux to biomass is minimal compared to the flux to metabolites. 


\section{Results}

Only steady-state results are reported in this paper. Steady-state was assumed when the absolute deviation of the time-averaged $\mathrm{NaOH}$ molar flow rate, captured over a period of at least $12 \mathrm{~h}$, did not exceed $10 \%$ of the mean value. The total accumulative timespan of the seven fermentations (runs) was $1300 \mathrm{~h}$, while only $31 \%$ of this period satisfied the steadystate criterion. The remainder of the time entailed the establishment of biofilm during start-up and recovery from undesirable events such as reactor drainage and $\mathrm{pH}$ probe/line blockages. Seven separate fermentations were performed (seven independent start-ups), while thirteen separate steady-states were achieved during these runs. The results from the steady-states are given in Table 1. Steady-states that were preceded by a prior steady-state (within the same fermentation run) are indicated in the last column of Table 1. For most steady-states, multiple HPLC samples were taken and accordingly average values are given in Table 1. Reproducibility of the steady-states was tested at dilution rates (D) of $0.11 \mathrm{~h}^{-1}$ (three steadystates), $0.32 \mathrm{~h}^{-1}$ (fives steady-states) and $0.72 \mathrm{~h}^{-1}$ (three steady-states). Single steady-states were performed at dilution rates of $0.054 \mathrm{~h}^{-1}$ and $0.52 \mathrm{~h}^{-1}$ in order to generate data over five distinct dilution rates to enhance any trends observed.

It is evident from Table 1 that the outlet steady-state condition is distinctly linked to D. When combining all steady-state measurements for a specific D, the standard deviation of the SA titre was calculated to be $6 \%\left(D=0.11 \mathrm{~h}^{-1}\right), 7 \%\left(D=0.32 \mathrm{~h}^{-1}\right)$ and $13 \%\left(D=0.72 \mathrm{~h}^{-1}\right)$. Accordingly all data at a given D was combined into a single set for subsequent analysis

(Fig. 3). The error bars in Fig. 3 represent the standard deviation of all steady-state measurements. No error bars are reported for dilution rates of $0.054 \mathrm{~h}^{-1}$ and $0.52 \mathrm{~h}^{-1}$ since repeat steady-states were not performed at these conditions. These results suggest that the biofilm performance is repeatable between different start-ups and that the metabolically 
Table 1 Summary of the results of thirteen separate steady-states at different dilution rates and for various independent fermentations

\begin{tabular}{ccccccccc}
\hline $\begin{array}{c}\text { Steady } \\
\text { state } \\
\text { no. }\end{array}$ & $\begin{array}{c}\mathrm{D} \\
\left(\mathrm{h}^{-1}\right)\end{array}$ & $\begin{array}{c}\text { Glucose } \\
\text { in } \\
\left(\mathrm{g} \mathrm{L}^{-1}\right)^{\mathrm{a}}\end{array}$ & $\begin{array}{c}\text { Time at } \\
\text { steady- } \\
\text { state } \\
(\mathrm{h})\end{array}$ & $\begin{array}{c}\text { SA } \\
\text { titre } \\
\left(\mathrm{g} \mathrm{L}^{-1}\right)\end{array}$ & $\begin{array}{c}\text { Max } \\
\text { deviation } \\
\text { of SA } \\
\text { titre } \\
\left(\mathrm{g} \mathrm{L}^{-1}\right)^{\mathrm{b}}\end{array}$ & $\begin{array}{c}\text { SA } \\
\text { yield } \\
\left(\mathrm{g} \mathrm{g} \mathrm{g}^{-1}\right)\end{array}$ & $\begin{array}{c}\text { Total } \\
\text { biomass } \\
\left(\mathrm{g} \mathrm{L}^{-1}\right)^{\mathrm{c}}\end{array}$ & $\begin{array}{c}\text { Previous } \\
\mathrm{D} \\
\left(\mathrm{h}^{-1}\right)\end{array}$ \\
\hline 1 & 0.054 & 51.4 & 24 & 32.5 & 0.4 & 0.90 & - & 0.11 \\
2 & 0.11 & 55.2 & 15 & 31.4 & 2.2 & 0.84 & 27.9 & 0.71 \\
3 & 0.11 & 50.0 & 24 & 28.0 & 2.1 & 0.89 & - & 0.31 \\
4 & 0.11 & 51.9 & 80 & 29.5 & 1.3 & 0.90 & - & 0.31 \\
5 & 0.32 & 33.6 & 30 & 22.2 & 1.8 & 0.83 & 23.7 & - \\
6 & 0.32 & 33.8 & 20 & 20.8 & 1.4 & 0.81 & - & - \\
7 & 0.31 & 35.0 & 20 & 20.2 & - & 0.85 & - & - \\
8 & 0.31 & 34.9 & 97 & 21.6 & 1.9 & 0.86 & - & - \\
9 & 0.31 & 56.1 & 24 & 19.4 & 0.5 & 0.83 & - & $0.31^{\mathrm{e}}$ \\
10 & 0.52 & 34.4 & 26 & 13.7 & 0.3 & 0.79 & 21.2 & - \\
11 & 0.71 & 34.6 & 32 & 14.1 & 1.5 & 0.80 & 22.4 & - \\
12 & 0.72 & 34.7 & 18 & 12.0 & - & 0.77 & - & - \\
13 & 0.72 & 32.1 & 16 & 11.3 & - & 0.82 & - & 0.054 \\
\hline
\end{tabular}

${ }^{a}$ Incorporates the dilution effect of $\mathrm{NaOH}$ and anti-foam dosing on the feed concentration.

${ }^{\mathrm{b}}$ Deviation from average. Blanks indicate single HPLC samples with steady $\mathrm{NaOH}$ dosing.

${ }^{\mathrm{c}}$ Suspended + attached biomass. Run terminated afterward measurement.

${ }^{\mathrm{d}}$ Prior steady-state (same fermentation). Blanks indicate constant dilution rates from start-up.

${ }^{\mathrm{e}}$ Preceded by steady state 8 . 
active fraction of the biofilm is similar for different runs. Furthermore, the results provide evidence that the steady-state biofilm characteristics are not dependant on the operational history. This can be inferred from the fact that some steady-states at a $\mathrm{D}$ of $0.11 \mathrm{~h}^{-1}$ were preceded by different prior steady-states (Table 1). In addition, the numerous disturbances that were experienced during the prolonged unsteady periods did not significantly affect the outcome once steady-state was established. The reproducibility of the steady-state conditions drastically simplifies the analysis of the biofilm reactor results.

The total biomass content was determined at the end of a fermentation run since the bioreactor was completely disassembled hence preventing further operation. Accordingly, steady-states with a corresponding total biomass reading (Table 1) represent the final steadystate within a fermentation run. Biomass measurements were obtained for each of the dilution rates except $\mathrm{D}=0.054 \mathrm{~h}^{-1}$ (Table 1 and Fig. 3). Apart from the slightly higher value at $\mathrm{D}=$ $0.11 \mathrm{~h}^{-1}\left(27.9 \mathrm{~g} \mathrm{~L}^{-1}\right)$, the total biomass amounts were very similar $\left(23.8 \pm 2.9 \mathrm{~g} \mathrm{~L}^{-1}\right)$. This is in direct agreement with the findings of Wee et al. (2002), where the total biomass content was independent of D in a hollow-fibre fermenter using immobilised Enterococcus faecalis. This likely indicates that the available attachment area, which was the same for all runs, governs the extent of biofilm accumulation and that the concentration of acids in the medium has minimal influence on the biofilm amount at steady-state.

Suspended biomass amounts in the fermenter effluent were analysed for all steady-states. Despite the lengthy collection time of the sample, which helped to average-out minor fluctuations in the biomass concentration, no observable trend was found with regard to dilution rate. The DCW values ranged between $0.2 \mathrm{~g} \mathrm{~L}^{-1}$ and $2.5 \mathrm{~g} \mathrm{~L}^{-1}$. It was clear that substantial biofilm detachment or sloughing occurred at certain intervals resulting in high DCW values while other periods were characterised by low suspended DCWs with a more 


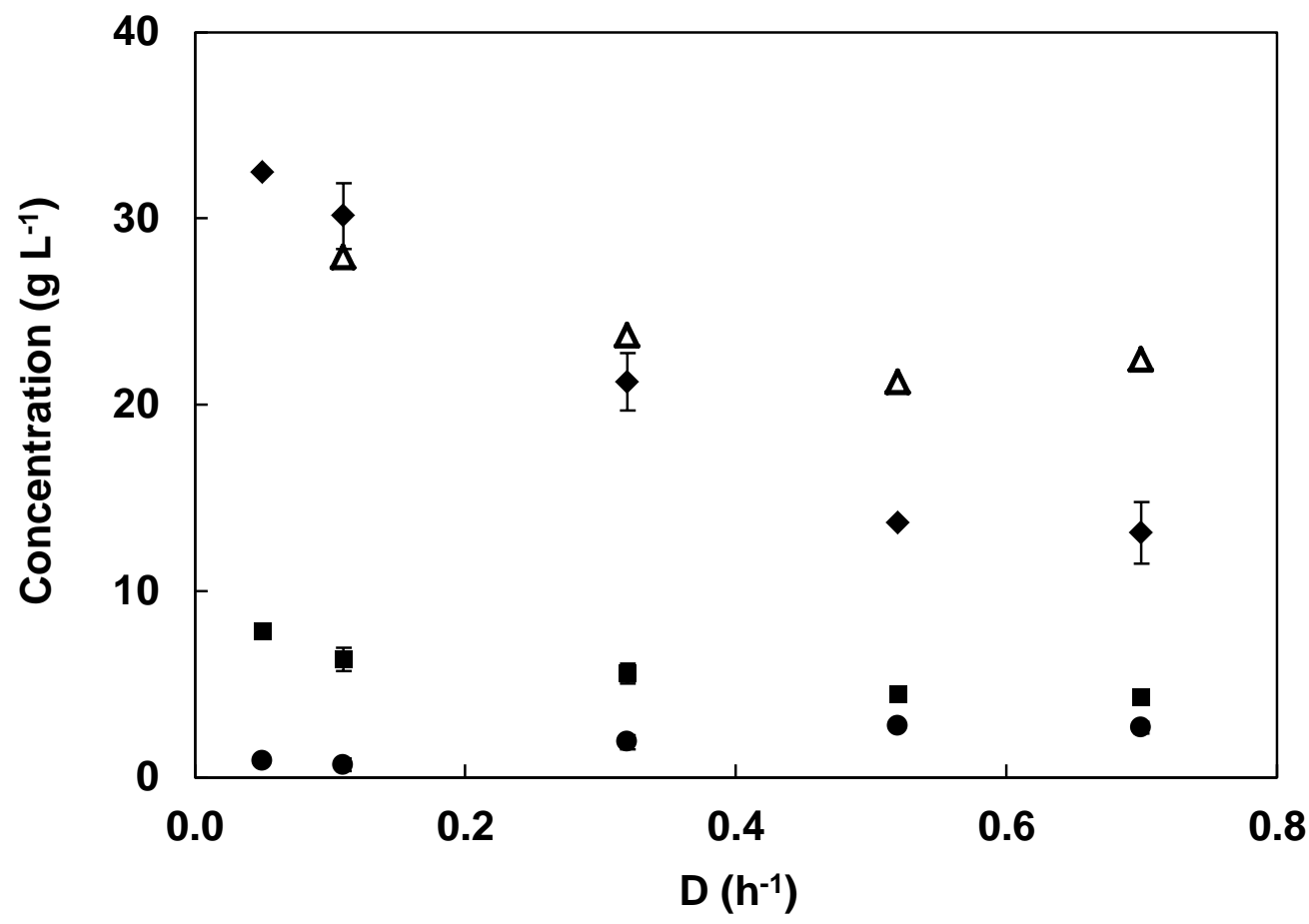

Fig. 3 Steady-state succinic acid (filled diamonds), acetic acid (filled squares), formic acid (filled circles) and total biomass (open triangles) concentrations at various dilution rates. Error bars represent standard deviation of all measurements. Error bars are not shown for dilution rates of $0.054 \mathrm{~h}^{-1}$ and $0.52 \mathrm{~h}^{-1}$ where repeat runs were not performed. 


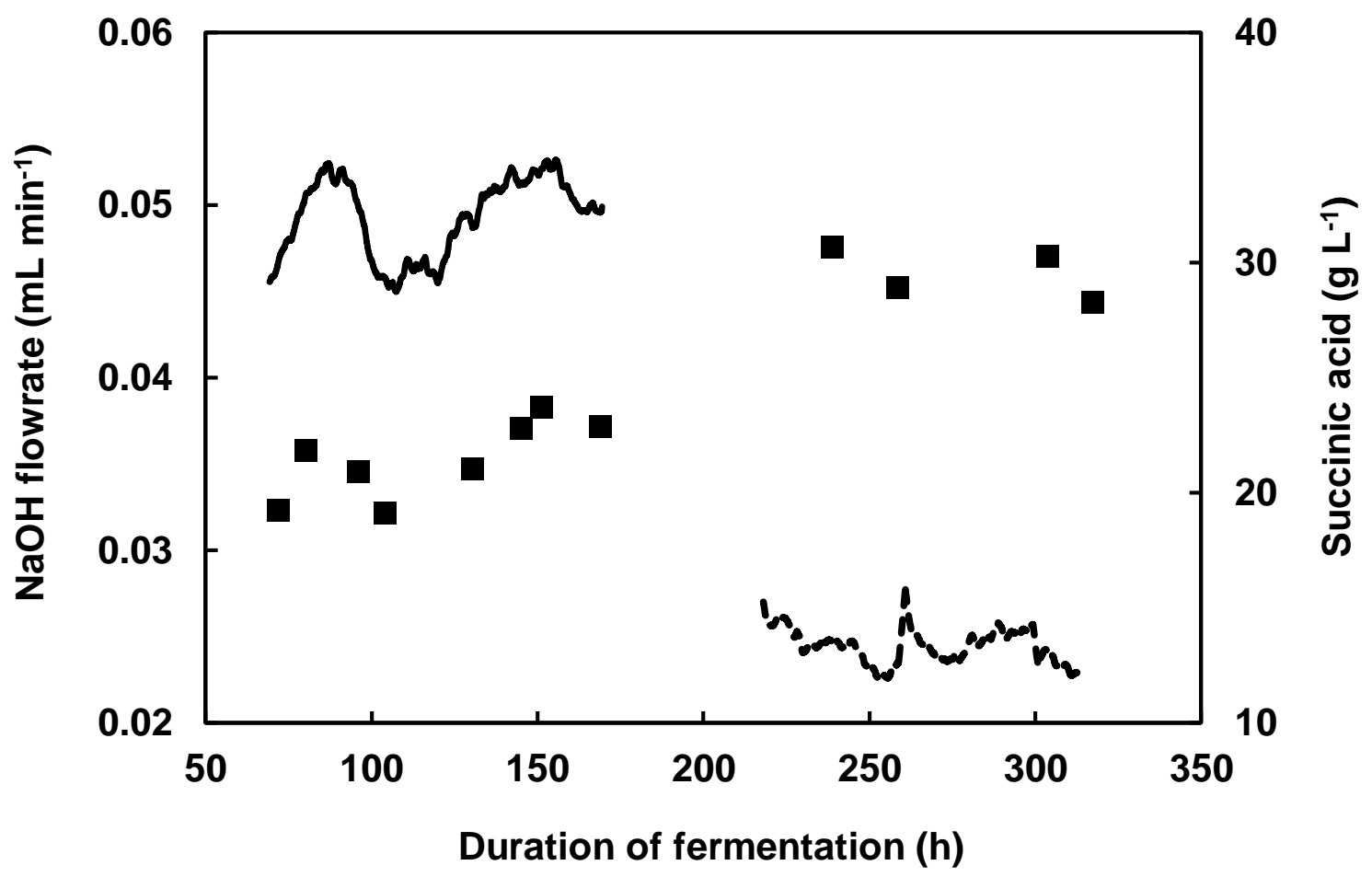

Fig. 4 Sodium hydroxide dosing profiles and succinic acid concentrations over time for steady-state conditions at two different dilution rates in a single fermentation. The black squares show the succinic acid concentration and the solid and broken lines represent the $\mathrm{NaOH}$ dosing profile at dilution rates of $0.32 \mathrm{~h}^{-1}$ and $0.11 \mathrm{~h}^{-1}$, respectively. 
stable biofilm. The influence of sloughing on the steady-state SA productivity was observed as an oscillatory behaviour of the outlet SA concentration. In Fig. 4, the $\mathrm{NaOH}$ dosing profiles as well as the SA titres of steady-states no. $4(\Delta \mathrm{t}=80 \mathrm{~h})$ and no. $8(\Delta \mathrm{t}=100 \mathrm{~h})$ are given. The standard deviation of the $\mathrm{NaOH}$ dosing flowrate was calculated to be $4.1 \%(\mathrm{D}=$ $\left.0.11 \mathrm{~h}^{-1}\right)$ and $4.6 \%\left(\mathrm{D}=0.32 \mathrm{~h}^{-1}\right)$. From Fig. 4 it is clear that the oscillatory behaviour of the steady-state at $\mathrm{D}=0.32 \mathrm{~h}^{-1}$ is more severe in amplitude although the frequency or cycle time appears to be longer than that of the $\mathrm{D}=0.11 \mathrm{~h}^{-1}$ run. No evidence of biofilm deactivation was observed during the two prolonged steady-states.

In Fig. 3, the average organic acid concentrations are given as well as the total biomass measurements. The standard deviations of all the steady-state measurements are presented as error bars for all the acids. The decreasing trend of SA and acetic acid (AA) concentrations against increasing D is to be expected, while the reverse trend for formic acid (FA) is unexpected. The same steady-state dataset was used to plot the overall yield on glucose (Fig. 5), the mass-based FA to AA ratio (Fig. 5), the mass-based SA to AA ratio (Fig. 6) and the SA productivity (Fig. 6). It is clear that the yield increased with decreasing dilution rates with the highest value of $0.9 \pm 0.013 \mathrm{~g} \mathrm{~g}^{-1}$ obtained at $\mathrm{D}=0.054 \mathrm{~h}^{-1}$. The increase in overall yield at lower dilution rates is supported by the increase in the SA to AA ratio and the gradual disappearance of formic acid (at lower dilution rates). High SA productivities were obtained at high D values where acid (product) inhibition is low. The highest productivity achieved in this study was $10.8 \mathrm{~g} \mathrm{~L}^{-1} \mathrm{~h}^{-1}$, which is the highest reported SA productivity using $A$. succinogenes to date. Although achieved at lower SA titre and yield, the value accentuates the extent of cell retention in the fermenter.

Effective inlet glucose concentrations (based on dilution caused by feed and average $\mathrm{NaOH}$ dosing flow rates) varied between $30 \mathrm{~g} \mathrm{~L}^{-1}$ and $35 \mathrm{~g} \mathrm{~L}^{-1}$ for $\mathrm{D}$ values of $0.3 \mathrm{~h}^{-1}$ and higher, $\mathrm{i}$ e $\mathrm{o}$ e $\mathrm{r}$ io of $\mathrm{o}$ ere $\mathrm{e}$ for $\mathrm{v}$ e of 


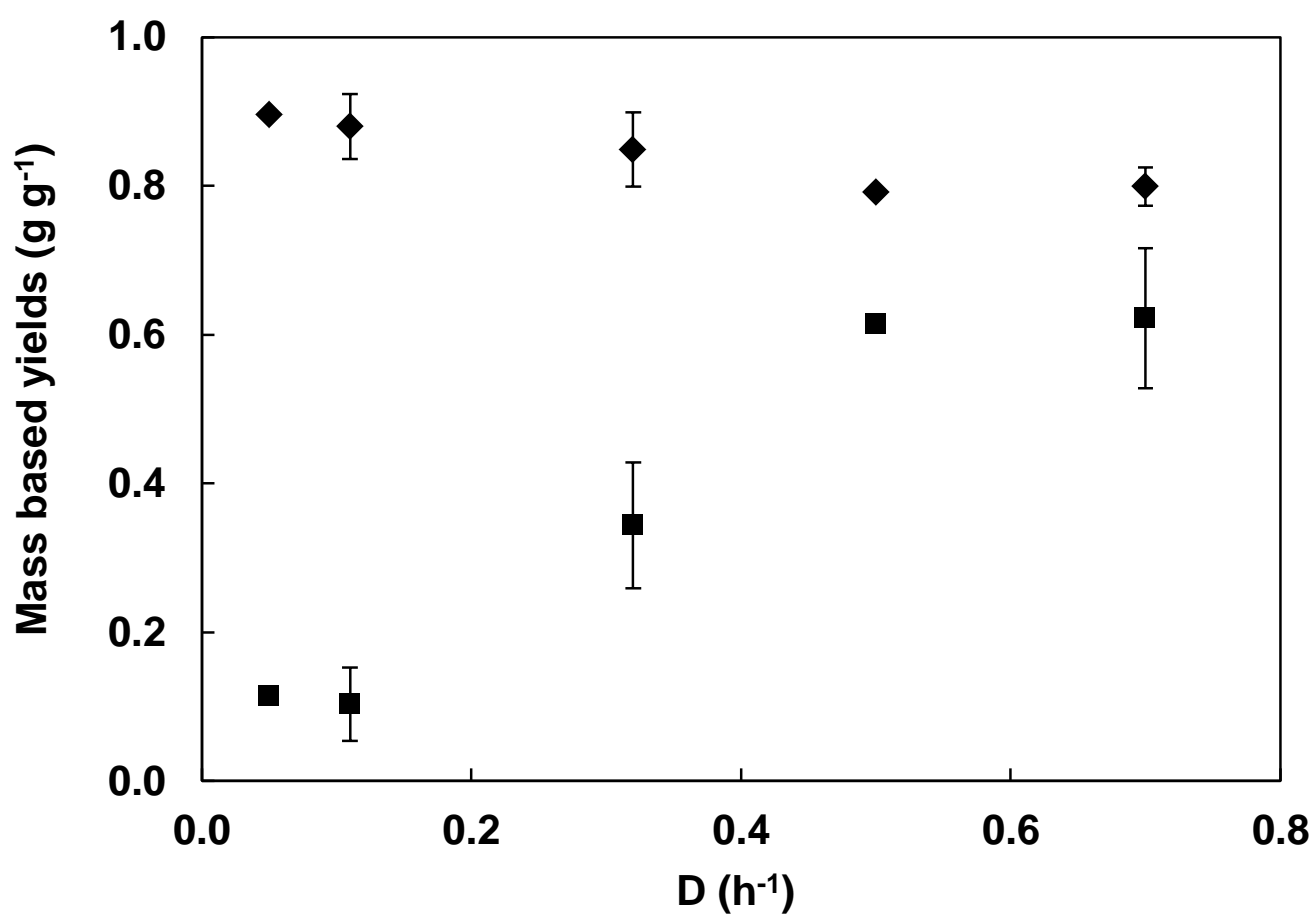

Fig. 5 Steady-state mass based yields (or ratios) of succinic acid to glucose (filled diamonds) and formic acid to acetic acid (filled squares) at various dilution rates. Error bars represent standard deviation of all measurements. Error bars are not shown for dilution rates of $0.054 \mathrm{~h}^{-1}$ and $0.52 \mathrm{~h}^{-1}$ where repeat runs were not performed. 


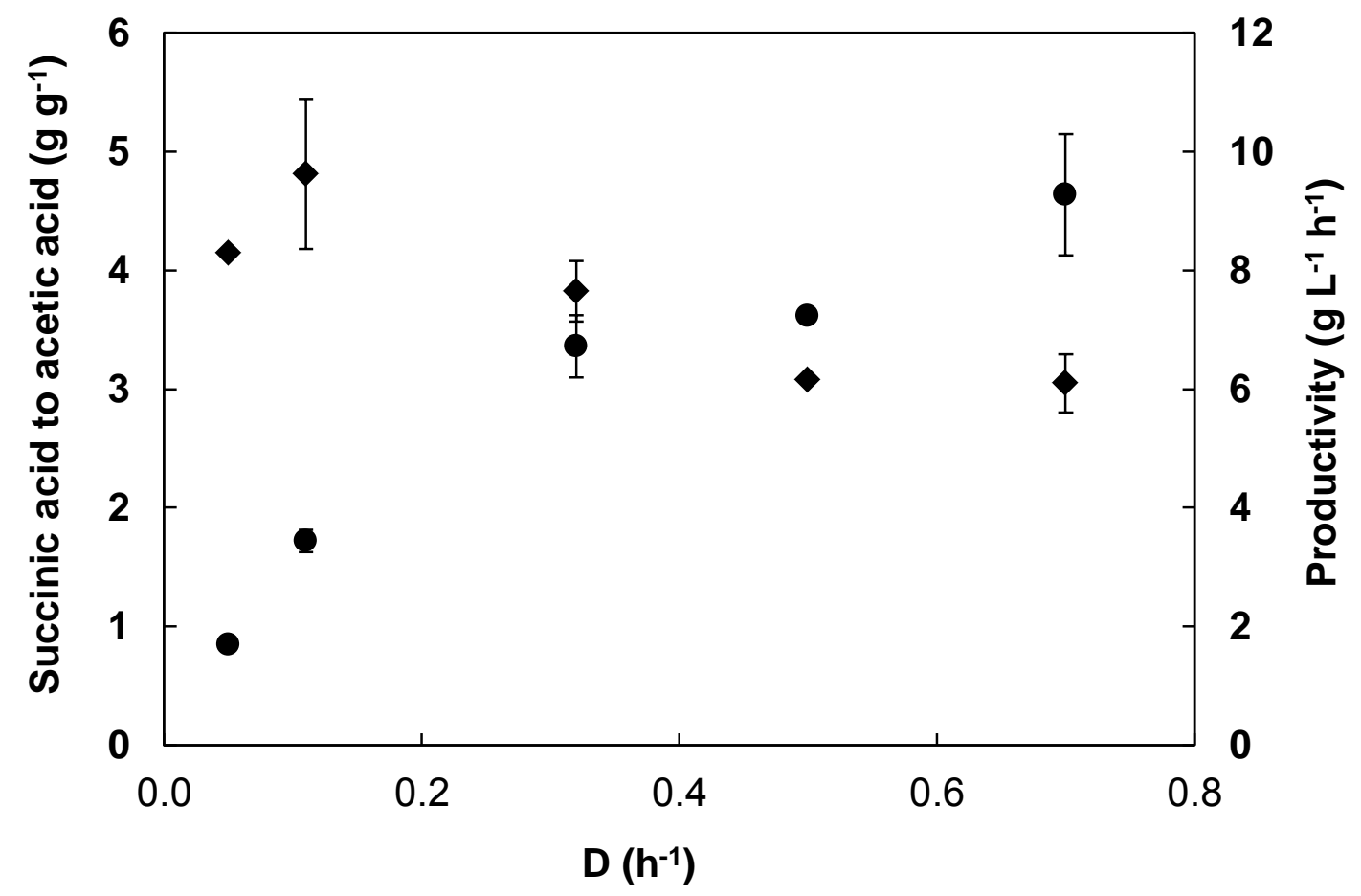

Fig. 6 Steady-state succinic acid to acetic acid mass yields (filled diamonds) and succinic acid volumetric productivities (filled circles) for various dilution rates. Error bars represent standard deviation of all measurements. Error bars not shown for dilution rates of $0.054 \mathrm{~h}^{-1}$ and $0.52 \mathrm{~h}^{-1}$ where repeat runs were not performed. 
below.

Steady-state no. 9 (Table 1) is the only exception, where the higher glucose concentration was used at $\mathrm{D}=0.32 \mathrm{~h}^{-1}$. The average $\mathrm{SA}$ titre reported at this steady-state was $8 \%$ lower than the average of all the data at $\mathrm{D}=0.32 \mathrm{~h}^{-1}$, hinting that substrate (glucose) inhibition might play a minor role. More data is required to thoroughly quantify glucose inhibition.

Although the paper is dedicated to steady-state behaviour, an interesting observation was made during the transient phase between steady-states. Lowering the $\mathrm{D}$ value from $0.32 \mathrm{~h}^{-1}$ to $0.11 \mathrm{~h}^{-1}$ resulted in an overshoot of the SA titre within the transient period between steadystates. The overshoot reached a maximum SA titre of $36 \mathrm{~g} \mathrm{~L}^{-1}$ which is higher than the steady-state average of $32.5 \pm 0.32 \mathrm{~g} \mathrm{~L}^{-1}$ at a $\mathrm{D}$ value of $0.054 \mathrm{~h}^{-1}$. 


\section{Discussion}

All the continuous studies on A.succinogenes (Bradfield and Nicol 2014; Van Heerden and Nicol 2013b; Kim et al. 2009; Urbance et al. 2004) have resulted in unavoidable biofilm formation. None of these studies were able to prove repeatability of the steady-state at a given D. This is most likely linked to the available area for attachment and the stability of attachment on the interfacial surfaces. The current study is the first to employ Poraver® beads as packing and the results exhibit superior stability and repeatability when compared to previous studies of a similar nature. Self-immobilisation for achieving cell retainment is attractive from a productivity and an equipment cost perspective, but process stability and repeatability should be considered as prerequisites. In this regard, the results presented in this paper are promising. It was shown that the steady-state biomass content and the reactor performance are independent of the start-up and operational history. In addition, the steadystate stability was shown to be acceptable, especially at low dilution rates where higher titres and yields were achieved.

Given the measured total biomass content in the fermenter, the specific productivities of the acid products were determined (Fig. 7). A distinct increase in biomass activity with increasing D is observed, with a fourfold increase in the SA specific productivity. Various factors can contribute to this observation. The fraction of metabolically active cells might decrease at higher acid titres where dead cells remain part of the biofilm. It is also plausible that the predominantly maintenance (or non-growth) state of acid production at lower D values (Bradfield and Nicol 2014) is much slower than the corresponding amounts at higher D values, where growth-linked production of acids is possible due to the smaller total acid concentration (Corona-González et al. 2008). Alternatively, the composition of the biomass might be linked to the condition in the bioreactor, with the extracellular polymeric substances 


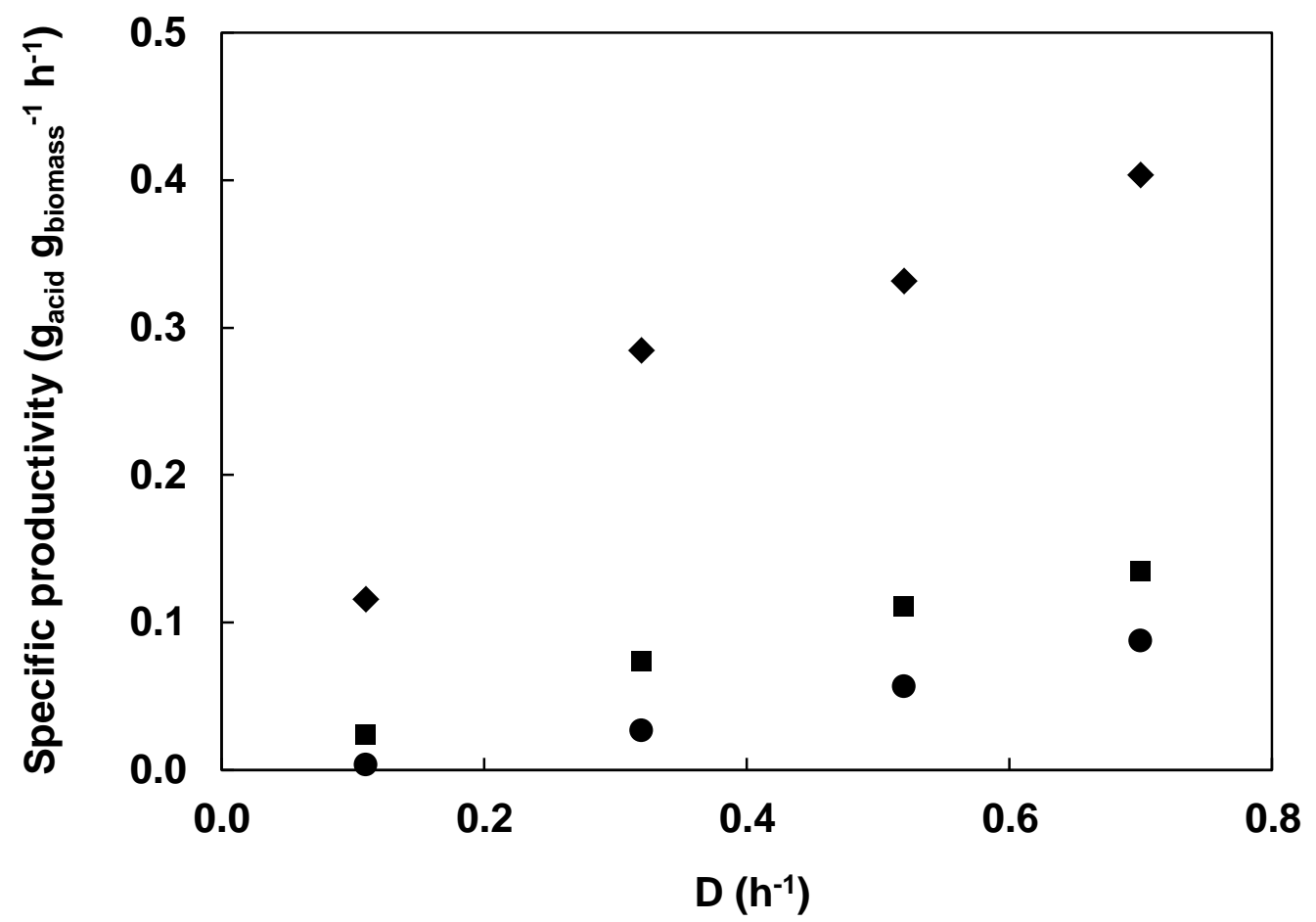

Fig. 7 Specific productivities of succinic acid (filled diamonds), acetic acid (filled squares) and formic acid (filled circles) at steady-state for various dilution rates. The specific productivity is based in the total biomass content in the reactor. 
(EPS) content varying between different steady-states. No qualitative data are available on the EPS fraction of the biomass since attempts to separate EPS from cells failed.

The observed steady-state oscillations are linked to a constant change within the biofilm matrix. It is well established that growth of A. succinogenes is inhibited by the total concentration of acids in the medium (Corona-Gonzalez et al. 2010; Corona-González et al. 2008; Lin et al. 2008; Urbance et al. 2004) and accordingly lower D values will result in slower growth. This was clearly observed during start-up periods, where operation at higher D values $\left(>0.5 \mathrm{~h}^{-1}\right)$ resulted in a faster establishment of biofilm. Although growth was faster at high D values, process instability was more severe due to biofilm-shedding events which led to violation of the steady-state criterion and as a result steady-state was more difficult to achieve and maintain. At lower D values $\left(<0.32 \mathrm{~h}^{-1}\right)$ this did not occur as is evident from the $\mathrm{NaOH}$ dosing profiles and SA concentration in Fig. 4. The degree of dosing oscillation at $\mathrm{D}=$ $0.32 \mathrm{~h}^{-1}$ as compared to that of $\mathrm{D}=0.11 \mathrm{~h}^{-1}$ is most likely linked to the growth activity of the biofilm. At low D the majority of acid production is linked to maintenance or non-growth metabolism (Bradfield and Nicol 2014) while only a small fraction of the total biomass is physically replicating. This is supported by the mass balance data (Materials and methods) where good closures were obtained by excluding suspended DCWs. The extent of growth, which increases with $\mathrm{D}$, causes instability in the attached biomass and results in shedding of significant biofilm segments. This is followed by re-growth on the vacant segments where lower acid concentrations at higher D values assist in faster regrowth. These cycles are more severe at $\mathrm{D}=0.32 \mathrm{~h}^{-1}$ as observed in Fig. 4 .

The yield ratios reported in Fig. 5 and Fig. 6 clearly exhibit that high titre production of SA is associated with high SA yields. The results are in direct agreement with the analysis by Bradfield and Nicol (2014) and reflect similar yields, titres and shifts in the metabolic flux 
distribution. These shifts include a decrease in formate and an increase in the SA to AA ratio at higher glucose consumption. Formate production tends towards zero at low D either by an increase in the activity of pyruvate dehydrogenase or formate dehydrogenase. The increase in the SA to AA ratio exceeds the theoretical maximum ratio of $3.93 \mathrm{~g} \mathrm{~g}^{-1}$ (Bradfield and Nicol 2014) indicating the presence of an unknown source of reducing power. The yield obtained at $\mathrm{D}=0.054 \mathrm{~h}^{-1}$ of $0.90 \pm 0.01 \mathrm{~g} \mathrm{~g}^{-1}$ is close to the highest reported SA yield of $0.94 \mathrm{~g} \mathrm{~g}^{-1}$ achieved with A. succinogenes in a batch fermenter (Guettler et al. 1996).

The results as a whole are promising from a production perspective. Reproducible and history-independent steady-state results were obtained at a set throughput while adequate production stability was achieved. Lower throughputs resulted in higher SA titre, improved production stability, less by-product formation and a higher overall SA yield.

\section{Acknowledgements}

The financial assistance of the National Research Foundation (NRF) towards this research is hereby acknowledged. Opinions expressed and conclusions arrived at are those of the author and are not necessarily to be attributed to the NRF. 


\section{References}

Balzer GJ, Thakker C, Bennett GN, San KY (2013) Metabolic engineering of Escherichia coli to minimize byproduct formate and improving succinate productivity through increasing $\mathrm{NADH}$ availability by heterologous expression of $\mathrm{NAD}(+)$-dependent formate dehydrogenase. Metab Eng 20:1-8. doi: 10.1016/j.ymben.2013.07.005

Beauprez JJ, De Mey M, Soetaert WK (2010) Microbial succinic acid production: natural versus metabolic engineered producers. Process Biochem 45:1103-1114. doi: 10.1016/j.procbio.2010.03.035

Bechthold I, Bretz K, Kabasci S, Kopitzky R, Springer A (2008) Succinic acid: a new platform chemical for biobased polymers from renewable resources. Chem Eng Technol 31:647-654. doi: 10.1002/ceat.200800063

Bozell JJ, Petersen GR (2010) Technology development for the production of biobased products from biorefinery carbohydrates - the US Department of Energy's "Top 10" revisited. Green Chem 12:539. doi: 10.1039/b922014c

Bradfield MFA, Nicol W (2014) Continuous succinic acid production by Actinobacillus succinogenes in a biofilm reactor: steady-state metabolic flux variation. Biochem Eng $\mathrm{J}$ 85:1-7. doi: 10.1016/j.bej.2014.01.009

Casali S, Gungormusler M, Bertin L, Fava F, Azbar N (2012) Development of a biofilm technology for the production of 1,3-propanediol (1,3-PDO) from crude glycerol. Biochem Eng J 64:84-90. doi: 10.1016/j.bej.2011.11.012

Cheng KC, Demirci A, Catchmark JM (2010) Advances in biofilm reactors for production of value-added products. Appl Microbiol Biotechnol 87:445-56. doi: 10.1007/s00253-0102622-3

Corona-González RI, Bories A, González-Álvarez V, Pelayo-Ortiz C (2008) Kinetic study of succinic acid production by Actinobacillus succinogenes ZT-130. Process Biochem 43:1047-1053. doi: 10.1016/j.procbio.2008.05.011

Corona-González RI, Bories A, González-Álvarez V, Snell-Castro R, Toriz-González G, Pelayo-Ortiz C (2010) Succinic acid production with Actinobacillus succinogenes ZT130 in the presence of succinic acid. Curr Microbiol 60:71-7. doi: 10.1007/s00284-0099504-x

Cukalovic A, Stevens CV (2008) Feasibility of production methods for succinic acid derivatives: a marriage of renewable resources and chemical technology. Biofuels, Bioprod Biorefin 2:505-529. doi: 10.1002/bbb.105

Dagher SF, Ragout AL, Siñeriz F, Bruno-Bárcena JM (2010) Cell immobilization for production of lactic acid: biofilms do it naturally. Adv Appl Microbiol 71:113-48. doi: 10.1016/S0065-2164(10)71005-4 
Dishisha T, Alvarez MT, Hatti-Kaul R (2012) Batch- and continuous propionic acid production from glycerol using free and immobilized cells of Propionibacterium acidipropionici. Bioresour Technol 118:553-62. doi: 10.1016/j.biortech.2012.05.079

Fernando S, Adhikari S, Chandrapal C, Murali N (2006) Biorefineries: current status, challenges, and future direction. Energy \& Fuels 20:1727-1737. doi: $10.1021 /$ ef060097w

Gross R, Hauer B, Otto K, Schmid A (2007) Microbial biofilms: new catalysts for maximizing productivity of long-term biotransformations. Biotechnol Bioeng 98:112334. doi: 10.1002/bit.21547

Guettler M, Jain M, Rumler D (1996) Method for making succinic acid, bacterial variants for use in the process, and methods for obatining variants. US Patent 5,573,931

Jantama K, Zhang X, Moore JC, Shanmugam KT, Svoronos SA, Ingram LO (2008) Eliminating side products and increasing succinate yields in engineered strains of Escherichia coli C. Biotechnol Bioeng 101:881-93. doi: 10.1002/bit.22005

Kim MI, Kim NJ, Shang L, Chang YK, Lee SY, Chang HN (2009) Continuous production of succinic acid using an external membrane cell recycle system. J Microbiol Biotechnol 19:1369-1373. doi: 10.4014/jmb.0903.03034

Lin SKC, Du C, Koutinas A, Wang R, Webb C (2008) Substrate and product inhibition kinetics in succinic acid production by Actinobacillus succinogenes. Biochem Eng $\mathrm{J}$ 41:128-135. doi: 10.1016/j.bej.2008.03.013

Qureshi N, Annous BA, Ezeji TC, Karcher P, Maddox IS (2005) Biofilm reactors for industrial bioconversion processes: employing potential of enhanced reaction rates. Microb Cell Fact 4:24. doi: 10.1186/1475-2859-4-24

Rosche B, Li XZ, Hauer B, Schmid A, Buehler K (2009) Microbial biofilms: a concept for industrial catalysis?. Trends Biotechnol 27:636-43. doi: 10.1016/j.tibtech.2009.08.001

Transparency-Market-Research (2013) Succinic acid market - global industry analysis, size, share, growth, trends and forecast, 2012 - 2018.

http://www.transparencymarketresearch.com/succinic-acid.html. Accessed 19 February 2014

Urbance SE, Pometto AL, DiSpirito AA, Demirci A (2003) Medium evaluation and plastic composite support ingredient selection for biofilm formation and succinic acid production by Actinobacillus succinogenes. Food Biotechnol 17:53-65. doi: 10.1081/FBT-120019984

Urbance SE, Pometto AL, DiSpirito AA, Denli Y (2004) Evaluation of succinic acid continuous and repeat-batch biofilm fermentation by Actinobacillus succinogenes using plastic composite support bioreactors. Appl Microbiol Biotechnol 65:664-70. doi: 10.1007/s00253-004-1634-2 
Van Heerden CD, Nicol W (2013a) Continuous and batch cultures of Escherichia coli KJ134 for succinic acid fermentation: metabolic flux distributions and production characteristics. Microb Cell Fact 12:80. doi: 10.1186/1475-2859-12-80

Van Heerden CD, Nicol W (2013b) Continuous succinic acid fermentation by Actinobacillus succinogenes. Biochem Eng J 73:5-11. doi: 10.1016/j.bej.2013.01.015

Wee YJ, Yun JS, Kang KH, Ryu HW (2002) Continuous production of succinic acid by a fumarate-reducing bacterium immobilized in a hollow-fiber bioreactor. Appl Biochem Biotechnol 98-100:1093-104.

Werpy T, Petersen G (2004) Top value added chemicals from biomass, Volume 1 - Results of screening for potential candidates from sugars and synthesis gas. US Department of Energy. http://www1.eere.energy.gov/bioenergy/pdfs/35523.pdf. Accessed 24 February 2014

Zeikus JG, Jain MK, Elankovan P (1999) Biotechnology of succinic acid production and markets for derived industrial products. Appl Microbiol Biotechnol 51:545-552. doi: $10.1007 / \mathrm{s} 002530051431$ 